\title{
Characterization of PVDF/Graphene Nanocomposite Membranes for Water Desalination with Enhanced Antifungal Activity
}

\author{
Emilia Gontarek-Castro 1,*(D), Maria Krystyna Rybarczyk ${ }^{2} \mathbb{D}$, Roberto Castro-Muñoz ${ }^{1,3} \mathbb{D}^{\mathbb{D}}$, \\ Monica Morales-Jiménez ${ }^{4}$, Blanca Barragán-Huerta ${ }^{4}$ (D) and Marek Lieder ${ }^{1}$ (D)
}

Citation: Gontarek-Castro, E.; Rybarczyk, M.K.; CastroMuñoz, R.; Morales-Jiménez, M.; Barragán-Huerta, B.; Lieder, M. Characterization of PVDF/Graphene Nanocomposite Membranes for Water Desalination with Enhanced Antifungal Activity. Water 2021, 13, 1279. https://doi.org/10.3390/ w13091279

Academic Editor: Muhammad Wakil Shahzad

Received: 26 March 2021

Accepted: 28 April 2021

Published: 30 April 2021

Publisher's Note: MDPI stays neutral with regard to jurisdictional claims in published maps and institutional affiliations.

Copyright: (c) 2021 by the authors. Licensee MDPI, Basel, Switzerland. This article is an open access article distributed under the terms and conditions of the Creative Commons Attribution (CC BY) license (https:/ / creativecommons.org/licenses/by/ $4.0 /)$.
1 Department of Process Engineering and Chemical Technology, Faculty of Chemistry, Gdansk University of Technology, 11/12 G. Narutowicza St., 80-233 Gdansk, Poland; food.biotechnology88@gmail.com (R.C.-M.); lieder@pg.edu.pl (M.L.)

2 Department of Geotechnical Engineering, Faculty of Civil Engineering and Architecture, Lublin University of Technology, 40 Nadbystrzycka St., 20-618 Lublin, Poland; m.rybarczyk@pollub.pl

3 Tecnologico de Monterrey, Campus Toluca, Avenida Eduardo Monroy Cárdenas 2000, San Antonio Buenavista, Toluca de Lerdo 50110, Mexico

4 Escuela Nacional de Ciencias Biológicas, Instituto Politécnico Nacional, Avenida Wilfrido Massieu s/n, Unidad Profesional Adolfo López Mateos, Mexico City 07738, Mexico; mmoralesj1902@alumno.ipn.mx (M.M.-J.); bbarraganh@ipn.mx (B.B.-H.)

* Correspondence: emilia.gontarek@pg.edu.pl

\begin{abstract}
Seawater desalination is a worldwide concern for the sustainable production of drinking water. In this regard, membrane distillation (MD) has shown the potential for effective brine treatment. However, the lack of appropriate MD membranes limits its industrial expansion since they experience fouling and wetting issues. Therefore, hydrophobic membranes are promising candidates to successfully deal with such phenomena that are typical for commercially available membranes. Here, several graphene/polyvinylidene (PVDF_G) membranes with different graphene loading $(0-10 \mathrm{wt} \%)$ were prepared through a phase inversion method. After full characterization of the resulting membranes, the surface revealed that the well-dispersed graphene in the polymer matrix ( 0.33 and $0.5 \mathrm{wt} \%$ graphene loading) led to excellent water repellence together with a rough structure, and a large effective surface area. Importantly, antifungal activity tests of films indicated an increase in the inhibition percentage for PVDF_G membranes against the Curvularia sp. fungal strain. However, the antifungal surface properties were found to be the synergistic result of graphene toxicity and surface topography.
\end{abstract}

Keywords: membrane distillation; graphene; membranes; anti-fungal activity

\section{Introduction}

Due to the current lack of drinking water, there is an urgent need to develop advanced processes for its production from natural sources. State-of-the-art technologies enable the treatment of sea water using selective membrane processes, such as reverse osmosis (RO) [1], pervaporation (PV) [2], and membrane distillation (MD) [3]. The latter is more affordable and economical due to the lower temperatures and process pressures, along with a higher salt rejection rate and lower susceptibility to concentration polarization. Unfortunately, the drawbacks of existing membrane materials, mainly fouling and wetting susceptibility, significantly limit their use in MD as a method of water desalination. Therefore, it is necessary to design novel structural materials to exploit the full potential of this membrane process.

Membrane fouling mitigation has been one of the main research challenges over the last years [4]. The fouling in MD depends on the physicochemical composition of the feed solution provoking organic, inorganic, and biological fouling, whereas the operating 
parameters in MD also influence the fouling generation. In principle, the biological fouling (called biofouling) is initiated by the adhesion, growth, and replication of either bacterial or fungal species on the membrane surface [5]. The biofouling affects the membrane hydraulic permeability, which causes an increase in maintenance costs and the deterioration of the power density [6-8]. To date, a number of strategies, such as polymerization, chemical grafting, nanocomposite preparation, and surface coating, have been applied to obtain specific surface morphology and membrane properties $[9,10]$. When dealing with the use of any additive, the main disadvantage is weak interaction between the polymer and additives, which affects the long-term durability of the surface modification layer, further causing its release outside the membrane. Recent developments have shown that the modification of polymeric membranes with inorganic nanomaterials may improve the MD stability against different types of fouling [11], together with the upgrading of other important membrane properties (such as the mechanical and thermal properties of membranes) [12,13]. For instance, the hydrophobicity of graphene and its exceptional properties [14] make it a promising material for improving the performance of polymeric membranes toward MD. In our previous studies, we investigated the role of adhesive interactions activated at the water/graphene interface on the assisted vapor transport during MD tests, where the increase of the flux was observed in the membranes containing low graphene concentration when compared with pristine PVDF membrane [15]. In addition, graphene and graphene derivatives were reported to exhibit broad-spectrum antimicrobial and antifungal activity [16]. These properties of graphene-based nanostructures are based on their capacity to induce membrane and oxidative stress, which compromise bacterial and fungal proliferation and sporulation [17-19].

In this work, hydrophobic porous membranes were prepared based on polyvinylidene fluoride (PVDF) and different graphene nanoplatelets (GNP) loading. PVDF was chosen as a membrane component due to its low cost and good thermal, mechanical, and chemical stability. The role of the incorporated graphene in the polymeric membrane matrix was investigated in terms of membrane characterization (such as porosity, pore size, hydrophobicity, and roughness) and antifungal activity. To the best of our knowledge, we are the first to evaluate the antifungal activity of PVDF/GNP nanocomposite membranes. To evaluate the antifungal properties of the membranes, Curvularia sp. (closely related with the genus Cochliobolus) was chosen. This hyphomycete fungus causes severe crop losses worldwide and has been detected in drinking water distribution systems and in groundwater supply systems [20]. The membrane material used for water treatment should possess antifungal activity to mitigate membrane biofouling and to produce water free of microbial pathogens. Thus, for the antifungal test, we selected one of many examples of phytopathogenic fungus that can be found in water.

\section{Materials and Methods}

\subsection{Materials}

PVDF (Solef ${ }^{\circledR} 6020$, Solvay Specialty Polymers, Düsseldorf, Germany), graphene nanoplatelets (GNP), powder, hydrophobic (Sigma-Aldrich, Poznań, Poland), N-methyl-2pyrrolidone (NMP, ACS reagent $\geq 99.0 \%$, Sigma Aldrich, Poznań, Poland), and isopropanol (POCH, Gliwice, Poland) were used for membrane preparation. Fluorinert ${ }^{\mathrm{TM}}$ FC-40 (SigmaAldrich, Poznań, Poland) was used for overall porosity estimation.

\subsection{Membrane Preparation}

The polymeric solution was prepared by dissolving $11.7 \mathrm{wt} \%$ of PVDF powder in NMP under mechanical stirring for $24 \mathrm{~h}$ in $30^{\circ} \mathrm{C}$. After this, the solution was left for $3-4 \mathrm{~h}$ without stirring for the removal of bubbles. The membranes were later cast on a glass and spread with the micrometric film applicator (Elcometer) using a gap size of $250 \mu \mathrm{m}$, immersed sequentially for $10 \mathrm{~min}$ in isopropanol, and cleaned with deionized water. Then, the membranes were dried at room temperature overnight. For PVDF/graphene membrane preparation, GNP were first dispersed in NMP using an ultrasonic bath alternated with 
mechanical stirring for $1.5 \mathrm{~h}$. PVDF was then added to the mixture, and the membranes were prepared analogously to the PVDF ones. The GNP loading in PVDF membranes ranged from 0.33 to $10 \mathrm{wt} \%$, and the membranes were named PVDF_0.33G, PVDF_0.5G, PVDF_5G, and PVDF_10G according to the GNP content.

\subsection{Membrane Characterization}

The morphology of the resulting membranes was analyzed using scanning electron microscopy (SEM, Zeiss-EVO MA10, Oberkochen, Germany) and an atomic force microscope. The atomic force microscopy was performed in a MultiMode 8, Nanoscope $\mathrm{V}$ (Veeco-Bruker, Plainview, NY, USA) using tapping mode and $5 \times 5 \mu \mathrm{m}$ of scan size. The average roughness $(\mathrm{Ra})$ and the root mean square roughness $(\mathrm{Rq})$ were calculated from the obtained images in NanoScope Analysis 1.4 software (Bruker Corporation, Billerica, MA, USA). The overall porosity is expressed as the total void inside the membrane. The pore size was estimated according to the gas-liquid displacement technique using a capillary flow porometer (PM, Instruments, CFP 1500, AXEL, Ithaca, NY, USA). The resistance to wetting with pure water was investigated by measuring the contact angle value (OCA 15 apparatus, Dataphysics, Filderstadt, Germany). Fourier transform infrared spectroscopy (FTIR) was used to collect spectra of the membranes in the scan range of $400-4000 \mathrm{~cm}^{-1}$ in ATR mode with a resolution of $16 \mathrm{~cm}^{-1}$ using a Nicolet iS10 FTIR spectrometer (Thermo Scientific Instrument Co., Boston, MA, USA). The X-ray diffraction patterns were recorded using an X-ray diffractometer (XRD, Rigaku MiniFlex 600, The Woodlands, TX, USA) in the range of $2 \theta=5-80^{\circ}$ with $\mathrm{Cu}-\mathrm{K} \alpha$ radiation.

\subsection{Antifungal Activity}

The antifungal activity assay was performed on natural potato dextrose agar (PDA), prepared according to the procedure described in the literature [21]. Both $0.37 \mathrm{mg} / \mathrm{mL}$ of lincomycin and $0.37 \mathrm{mg} / \mathrm{mL}$ of chloramphenicol were used to minimize contamination with bacteria. The antifungal activity assay was tested on Curvularia sp. fungal species according to the method described previously [22]. All PVDF/GNP membranes were cut in square sized pieces $(1 \times 1)$ and assayed; pristine PVDF membrane was also evaluated and taken as a negative control and bioactive film from microalgae-based biopolymer as a positive control. The square-shaped membranes were placed on the center of PDA plates. After inoculation with a mycelial plug on the film surface, plates were incubated for three days at $28^{\circ} \mathrm{C}$ in the dark. All trials were performed three times. The radial growth was measured and is expressed in $\mathrm{cm}$, and the inhibition percentage was calculated using Equation (1), as follows:

$$
\begin{gathered}
\text { Inhibition }(\%)=\frac{\text { negativecontrolarea }- \text { treatmentarea }}{\text { negativecontrolarea }} \times 100 \% \\
\text { area }=\pi \times r^{2}
\end{gathered}
$$

\section{Results and Discussion}

The characteristics and morphologies of the pristine and PVDF/GNP membranes are shown in Table 1. Although all the fabricated membranes showed highly porous structures between $64 \%$ and $77 \%$, the composition of the membrane significantly influenced the membrane morphology and surface properties, such as roughness, pore size, and hydrophobicity. The surface of the pristine PVDF and PVDF/GNP membranes was analyzed by SEM, as shown in Figure 1. The analysis confirmed a successful incorporation of graphene nanoplatelets into the PVDF matrix. The pristine PVDF showed a sponge-like structure and relatively smooth surface, which is typical for porous polymeric membranes [23]. With the addition of graphene, this structure became more compact. This was confirmed by slightly reduced overall porosity values and a significant reduction in pore size, (especially for PVDF_5G and PVDF_10G), for which a smaller value was detected (from $0.5 \mu \mathrm{m}$ to 0.27 and $0.24 \mu \mathrm{m}$, respectively). In the graphene-incorporated PVDF membranes, where GNP 
were uniformly distributed in the membrane matrix (PVDF_0.33G and PVDF_0.5G), an enhancement in surface roughness was observed (Figure 1D,F). Nevertheless, with excess addition of GNP, they aggregated in the membrane matrix, as exhibited by PVDF_5G and PVDF_10G (Figure 1G,I). This led to porosity and pore size reduction, while the surface morphology tuned by the graphene incorporation was expected to affect the surface hydrophobicity. Similar results were observed previously when the aggregation of the graphene nanoparticles in the membrane matrix led to a smaller pore size, lower porosity, and increased thickness of the fabricated membranes [24].

In practice, the hydrophobicity of the surface depends on the high surface roughness and low surface energy of materials [25]. Moreover, the hydrophobicity in MD membranes is of particular importance, since it maintains the gas phase in the pores, which is required for MD. Thus, the surface roughness of the membranes has a strong influence on their wetting performance. For instance, the AFM images of all the membranes are shown in Figure $1 \mathrm{~B}, \mathrm{D}, \mathrm{F}, \mathrm{H}, \mathrm{J})$, while the $\mathrm{Rq}$ and $\mathrm{Ra}$ values of the membranes and their surface area are reported in Table 1. The pristine PVDF membrane, according to the SEM and AFM images, possessed a smooth and microporous surface, and the measured value of the Rq was about $289 \mathrm{~nm}$. After incorporation of GNPs, the Rq parameter increased up to 524 and $375 \mathrm{~nm}$ for PVDF_0.33G and PVDF_0.5G, respectively. This confirms that graphene intercalation provides PVDF a rougher membrane surface. In general, the incorporation of nanomaterial in the polymeric membrane enhances its roughness, which is caused by the introduction of nano-scaled protrusions [26-28]. However, GNP aggregation, as observed for PVDF_5G and PVDF_10G, led to an Rq reduction of 292 and $183 \mathrm{~nm}$, respectively. Thus, the highly rough surface of the PVDF_0.33G and PVDF_0.5G membranes can be attributed to the well-dispersed graphene nanoplatelets in the membrane matrix [12]. In general, rough surfaces are able to form an air gap between the surface protrusions, creating a gas-liquid interface between the liquid and the membrane surface, which is beneficial to enhancing the anti-wettability and anti-fouling properties of the membranes in MD [29].

Table 1. Properties of the pristine PVDF membrane and its graphene-based composites. Porosity and mean pore size analyses were performed 3 times for every sample and the values are reported as mean \pm standard deviation.

\begin{tabular}{|c|c|c|c|c|c|}
\hline Membrane & Porosity (\%) & Mean Pore Size $(\mu \mathrm{m})$ & $\mathrm{Rq}(\mathrm{nm})$ & $\operatorname{Ra}(\mathrm{nm})$ & Surface Area $\left(\mu \mathrm{m}^{2}\right)$ \\
\hline PVDF & $77 \pm 2$ & $0.48( \pm 0.09)$ & 289 & 222 & 44.3 \\
\hline PVDF_0.33G & $77 \pm 2$ & $0.53( \pm 0.02)$ & 524 & 430 & 58.2 \\
\hline PVDF_0.5G & $69 \pm 2$ & $0.56( \pm 0.06)$ & 375 & 310 & 50.4 \\
\hline PVDF_5G & $65 \pm 3$ & $0.27( \pm 0.01)$ & 292 & 226 & 46.1 \\
\hline PVDF_10G & $64 \pm 6$ & $0.24( \pm 0.01)$ & 183 & 152 & 36.6 \\
\hline
\end{tabular}
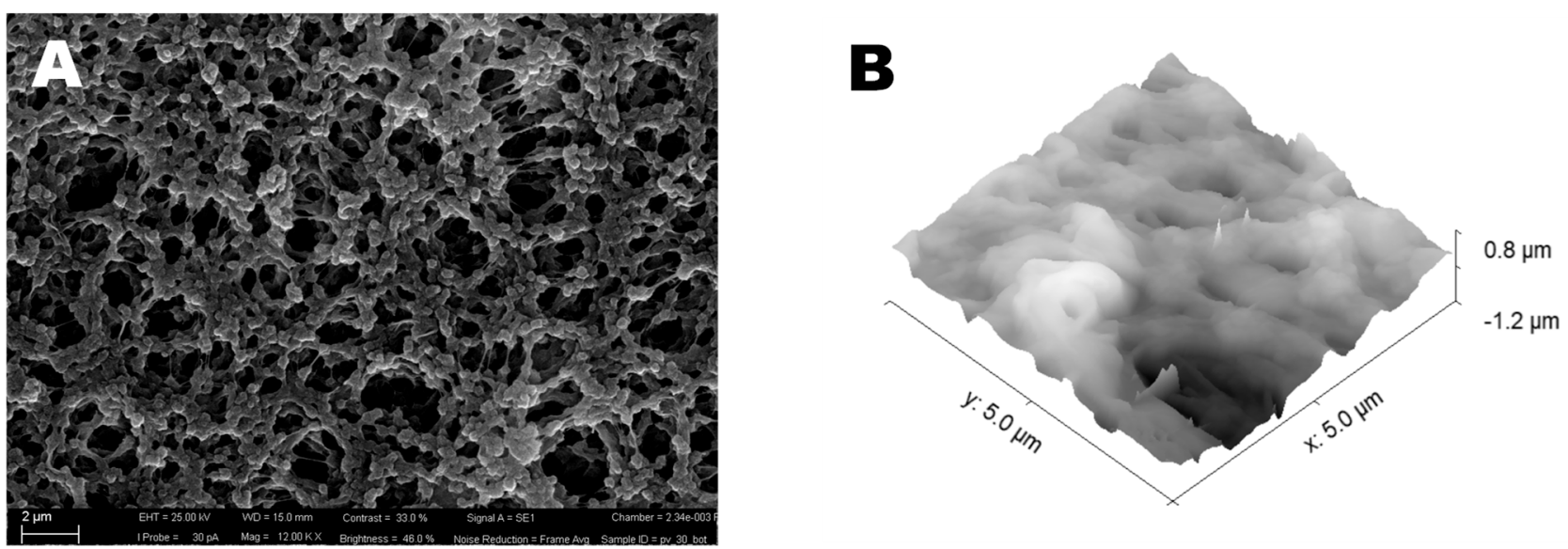

Figure 1. Cont. 

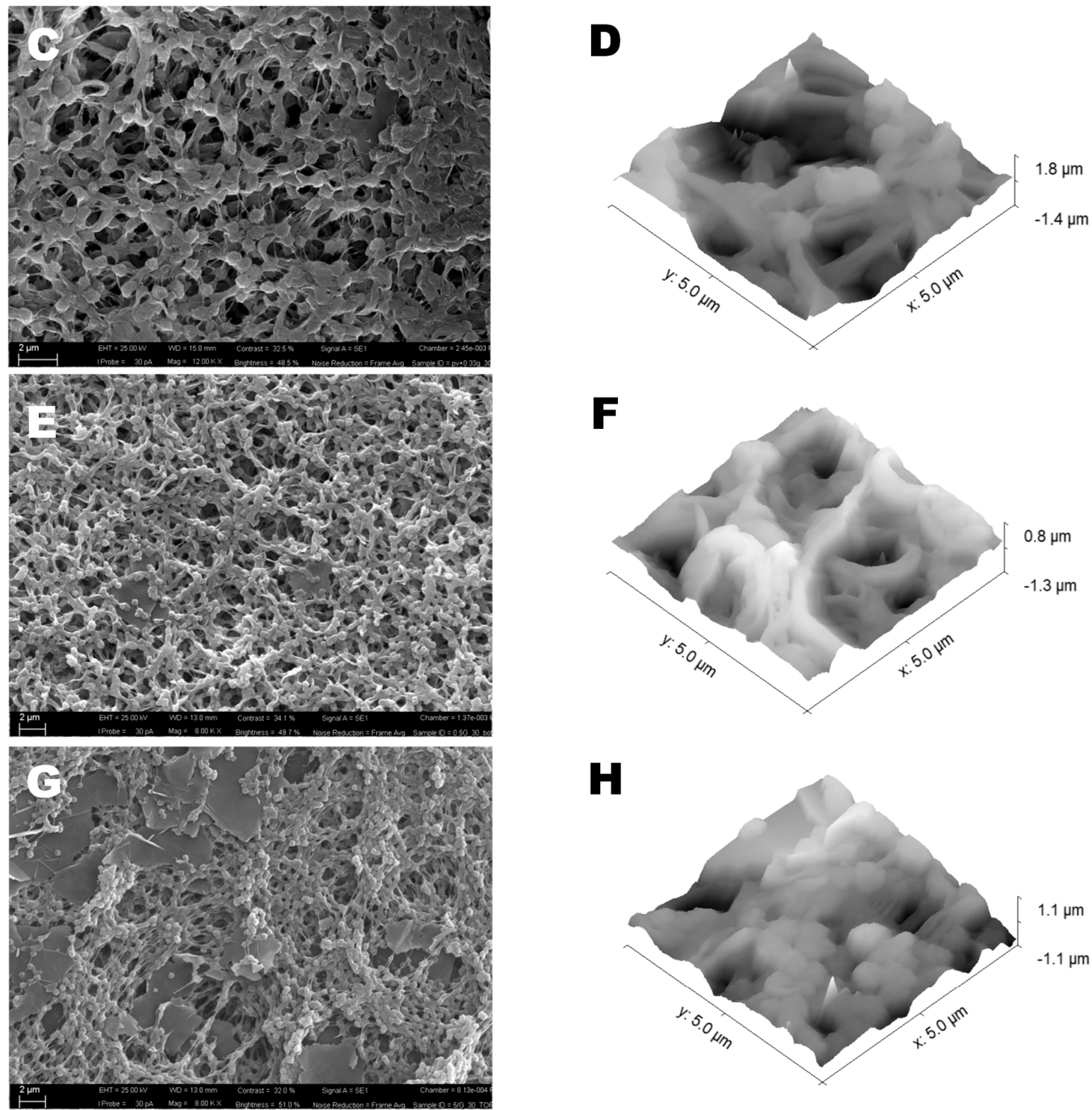

\section{H}
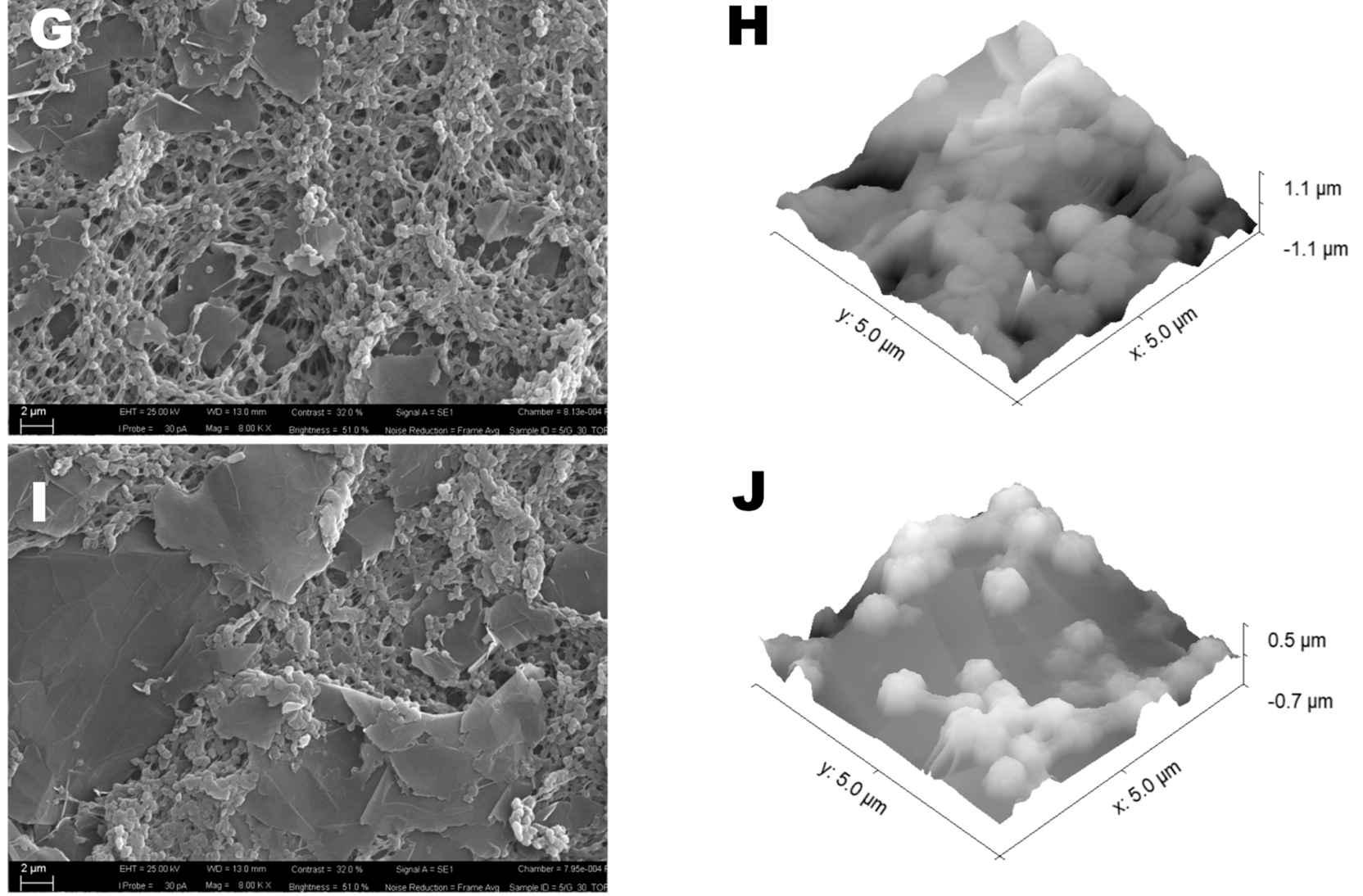

Figure 1. Top view SEM images (the scale bars in the images are $2 \mu \mathrm{m})$ and AFM 3D images $(5 \times 5 \mu \mathrm{m})$ of all the membranes: (A,B) pristine PVDF, (C,D) PVDF_0.33G, (E,F) PVDF_0.5G, (G,H) PVDF_5G, and (I,J) PVDF_10G. 
The wetting property of membranes is a crucial characteristic for MD membranes since it reduces the performance by blocking the passages of vapor [30]. Thus, the contact angle (CA) is an efficient indicator used to measure the wettability of a membrane surface; therefore, the $C A$ values of the resulting membranes surface toward water were measured and are illustrated in Figure 2. In principle, the initial water CA values were $110.9^{\circ} \pm 0.7^{\circ}$, $130.7^{\circ} \pm 0.9^{\circ}, 139.5^{\circ} \pm 1.6^{\circ}, 129.9^{\circ} \pm 2.2^{\circ}$, and $119.6^{\circ} \pm 2.2^{\circ}$ for pristine PVDF, PVDF_0.33G, PVDF_0.5G, PVDF_5G, and PVDF_10G, respectively. These results indicate that welldispersed GNP in a polymeric matrix improved the hydrophobicity of the fabricated membrane. However, the presence of GNP is not enough to impart suitable hydrophobic properties. For instance, PVDF_0.5G exhibited remarkable enhancement in hydrophobicity due to the highly enhanced surface roughness, as confirmed by AFM and SEM, whereas for PVDF_10G, only a slight increase was observed. In general, the CA values followed a similar trend as the surface roughness values described in the previous section. Importantly, the change in water CA value over time was determined. As shown in Figure 2, all of the samples showed a tendency of water droplets spreading on their surface over $30 \mathrm{~min}$ of observation. In the case of PVDF_0.5Gparticularly, the anti-wetting properties tended to be more stable over time, as it exhibited a decrease in the water CA value by only $8 \%$ (final water CA value equal $128.3^{\circ} \pm 2.3^{\circ}$ ). For other samples, a reduction in the water CA value by $15 \%, 13 \%, 15 \%$, and $14 \%$ was noted for pristine $\operatorname{PVDF}\left(94.5^{\circ} \pm 1.1^{\circ}\right)$, PVDF_0.33G $\left(113.7^{\circ} \pm 1.7^{\circ}\right)$, PVDF_5G $\left(110.1^{\circ} \pm 1.8^{\circ}\right)$, and PVDF_10G $\left(102.6^{\circ} \pm 2.9^{\circ}\right)$, respectively. Therefore, it is likely that the PVDF_0.5G membrane was sufficient to create a water-resistant surface.

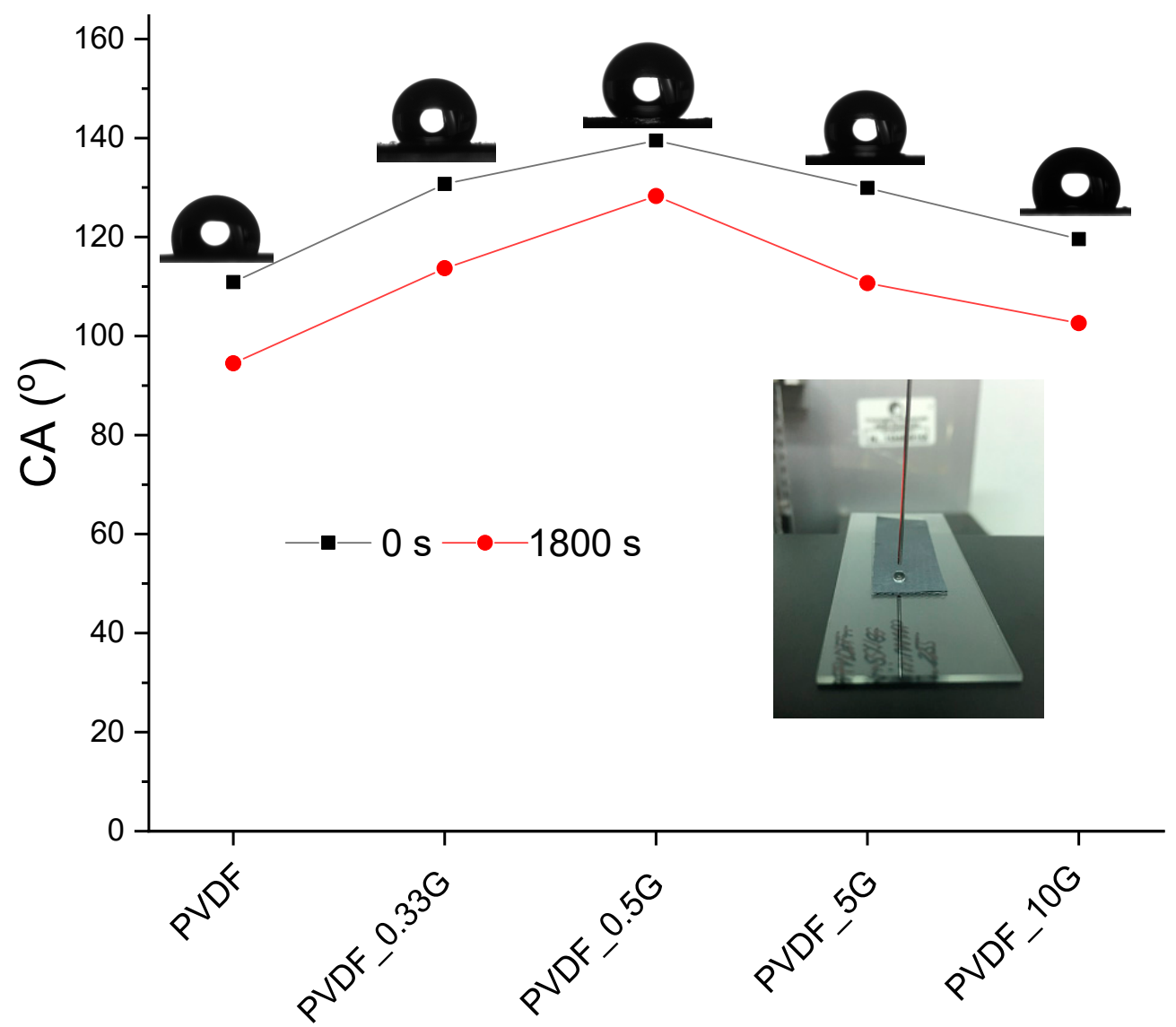

Figure 2. Water contact angle values for pristine PVDF membrane and its graphene-based composites. 
Figure 3 presents the FTIR spectra of all fabricated membranes. In general, pristine PVDF and graphene nanocomposite membranes revealed the same typical absorption bands and basic structural characteristics of PVDF. The strong peaks at 839, 875, 1074, 1175,1270 , and $1400 \mathrm{~cm}^{-1}$ correspond to $\mathrm{CH}_{2}$ rocking and $\mathrm{CF}_{2}$ asymmetric stretching, $\mathrm{C}-\mathrm{C}$ asymmetric stretching, $\mathrm{C}-\mathrm{C}$ asymmetric stretching, $\mathrm{CF}_{2}$ symmetric stretching, $\mathrm{CF}$ out-of-plane deformation, and $\mathrm{CH}_{2}$ wagging vibration, respectively [31,32]. This means that the addition of graphene did not produce any change in the membrane characteristics in terms of the crystalline phase. Particularly, an additional weak signal was observed for composites at $1730 \mathrm{~cm}^{-1}$. This represents the $\mathrm{C}=\mathrm{O}$ stretching of the carbonyl and carboxylic groups present on the graphene sheets [33]. Thus, this confirms the successful incorporation of nanofiller inside the PVDF matrix.

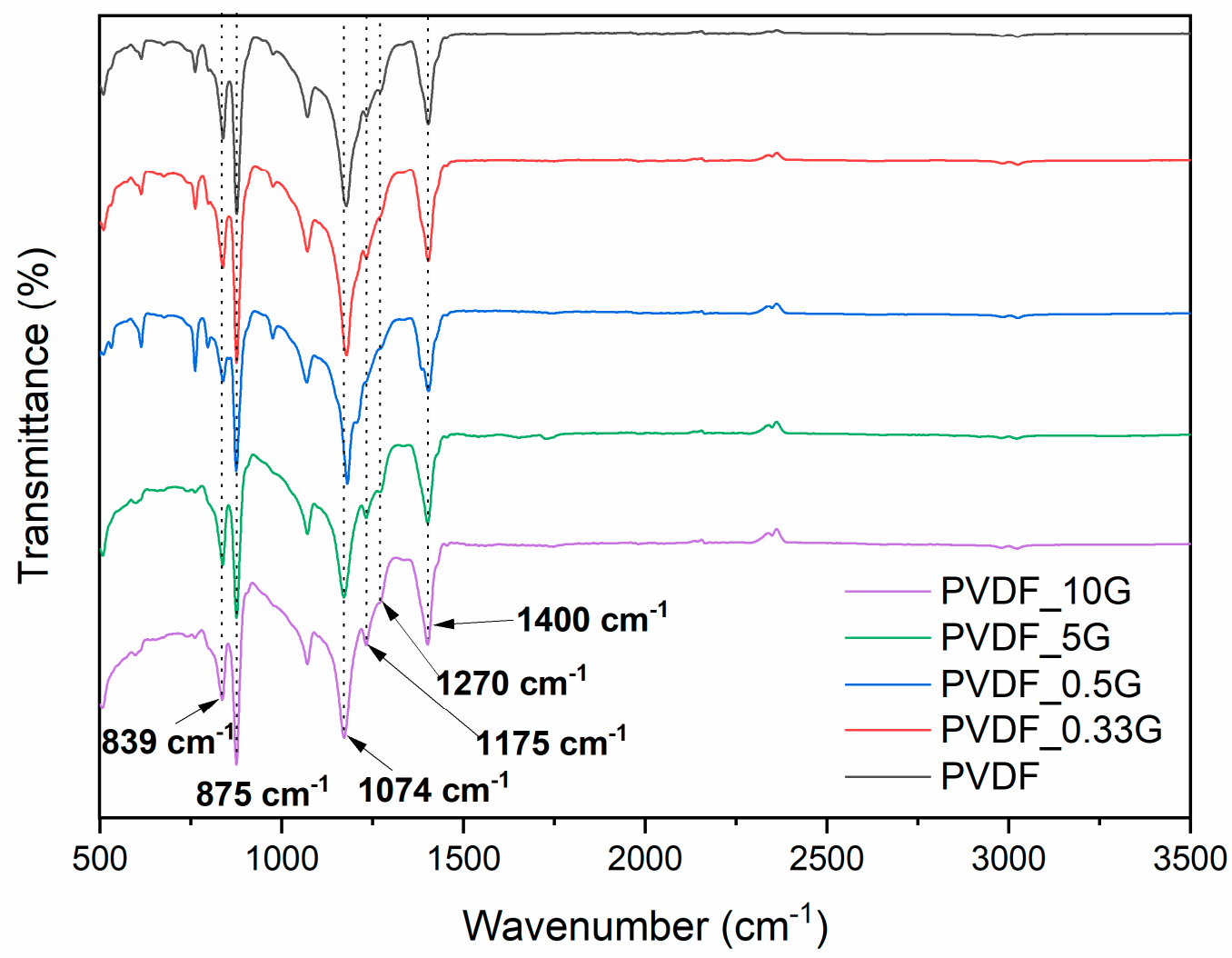

Figure 3. FTIR spectra comparison for pristine PVDF membrane and its graphene-based composites.

XRD analyses revealed the presence of the filler inside the membranes (Figure 4). The (002) and (004) peaks at $26.5^{\circ}$ and $54.6^{\circ}$, respectively, represent the perpendicular direction (c-axis) to the hexagonal planes of graphite [34]. They were detected in GNP material as well as in PVDF/GNP membrane patterns, and their intensity increased with raising concentration as an effect of GNP confinement in the polymer matrix. The rest of the signals in nanocomposite membranes were from the PVDF crystalline phase. For example, medium reflections at $18.4^{\circ}$ and $20^{\circ}$, and a weaker one at $35.9^{\circ}$, correspond to the reflections of 020,110 , and 200 of monoclinic $\alpha$-phase crystal, respectively, while the peak at $39.1^{\circ}$ refers to diffraction peak on the(211) planes of monoclinic $\gamma$-phase crystal [35]. 


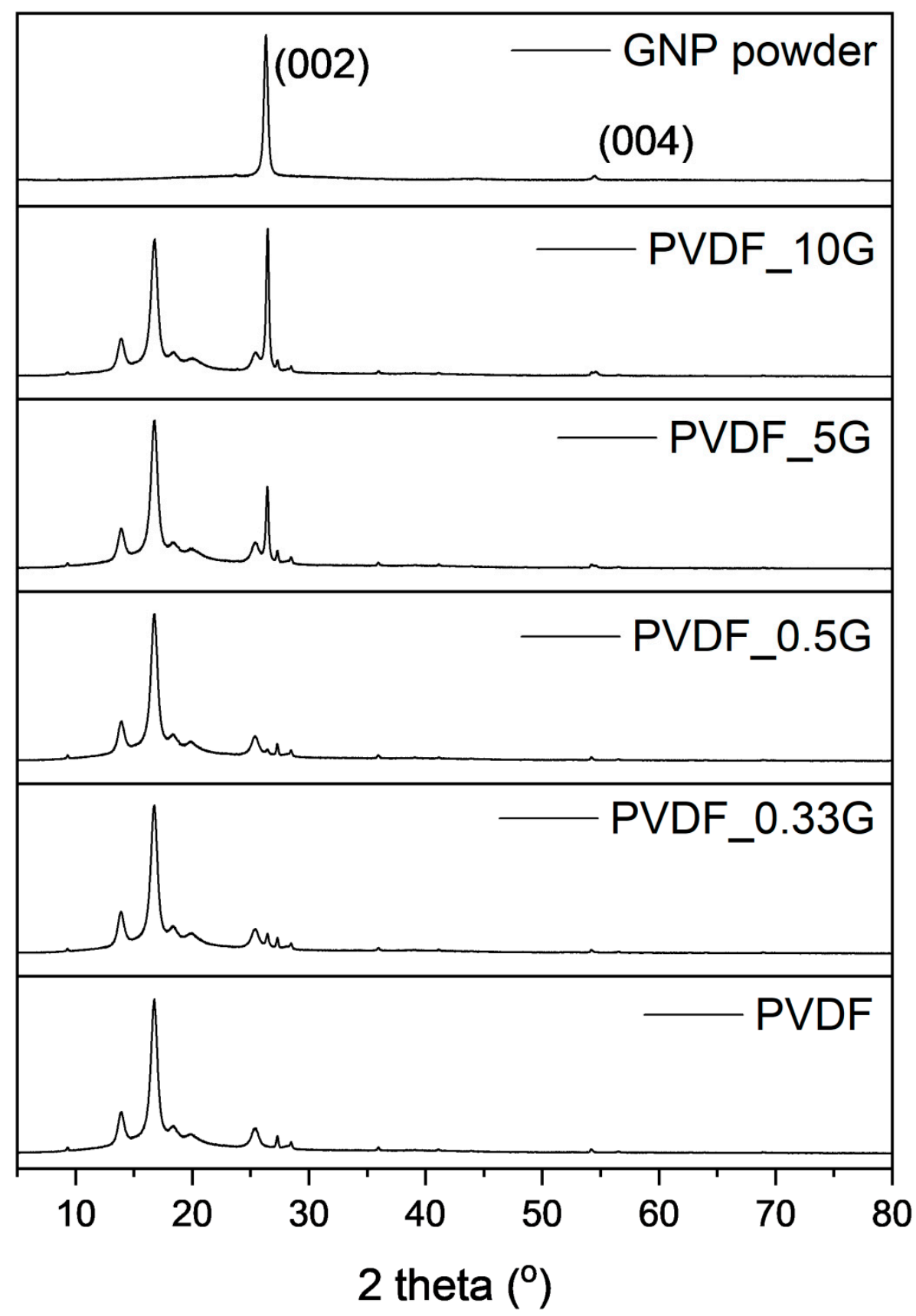

Figure 4. XRD patterns of pristine PVDF membrane and its graphene-based composites.

Figure 5 shows the inhibition percentage against Curvularia sp. fungal strain after $72 \mathrm{~h}$. The best growth inhibition was achieved by PVDF_0.33G and PVDF_0.5G membranes, with an inhibition percentage of $74.9 \%$ and $75.7 \%$, respectively. PVDF_5G exhibited a slightly lower inhibition percentage, reaching $61.7 \%$. Such obtained values are in the range of studies evaluating the antibacterial properties of graphene-based materials against E. coli, S. aureus [36], and B. subtilis [37], with values between $60 \%$ and 99\%. Pristine PVDF and PVDF_10G presented very weak antifungal activity in comparison with other samples. In general, there is a clear antimicrobial effect of the graphene when incorporated into PVDF membranes, as illustrated in Figure 6. 


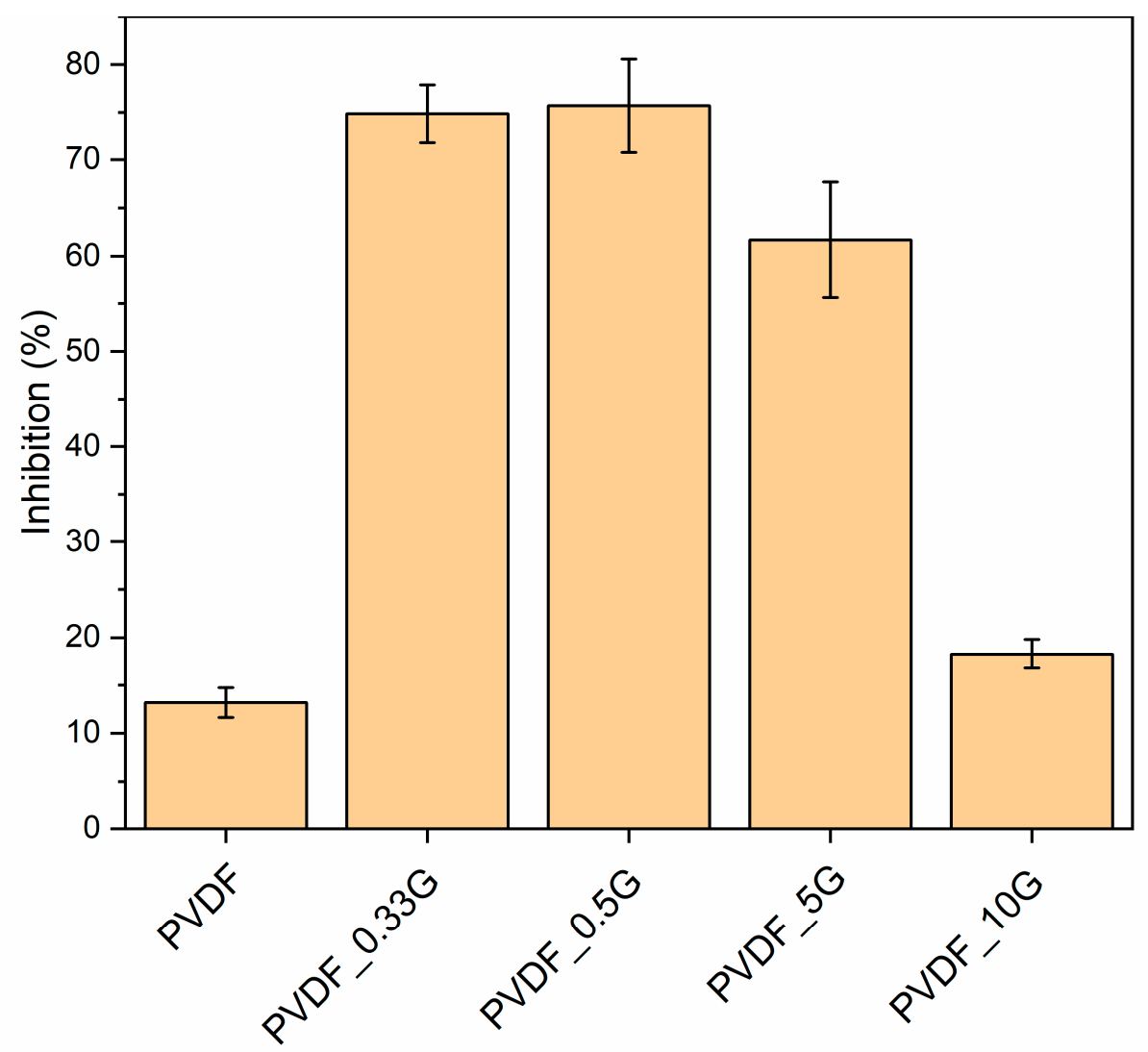

Figure 5. Antifungal inhibitions (\%) of all fabricated membranes against Curvularia sp. fungal strain.
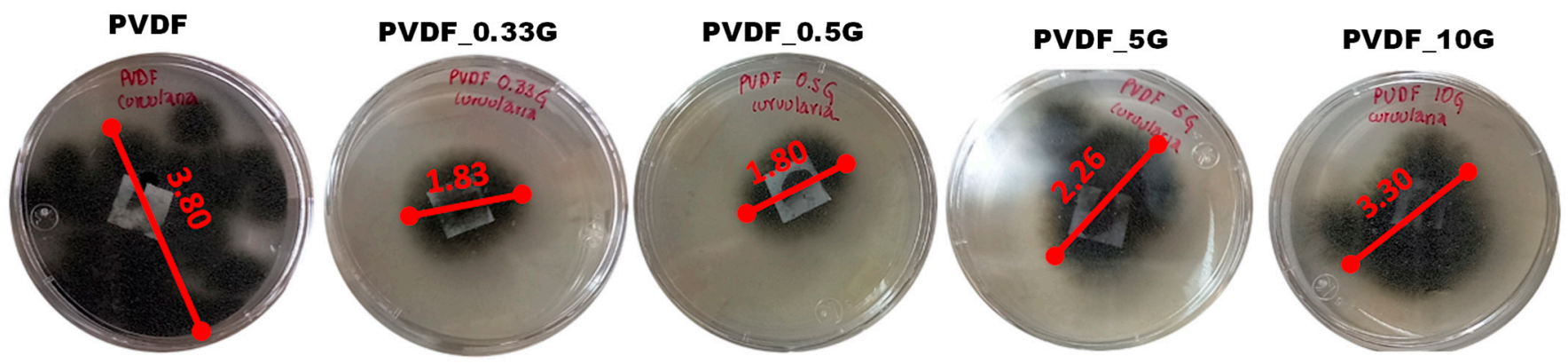

Figure 6. Photographs of antifungal inhibition of all fabricated membranes against Curvularia sp. fungal strain after $72 \mathrm{~h}$.

Notably, the antibacterial and antifungal mechanism of graphene materials was previously reported [38]. To date, graphene materials were also combined with other inorganic nanoparticles (such as $\mathrm{Ag}$, Ti, and Co) to attain 100\% antimicrobial inhibition [39]. Different studies revealed that direct contact with graphene nanowalls can damage bacterial cell membranes, inhibiting the growth of the microorganism due to their extremely sharp edges $[19,40]$. Nevertheless, it is the oxidative stress that is the major mechanism of graphene toxicity [41]. Moreover, its antimicrobial activity was also explained with electron transfer, as graphene acts as an electron acceptor and abstracts electrons from the bacterial membrane, which may adversely affect the integrity of the membrane [42]. Notably, the presence of graphene in the membranes does not appear to be sufficient to provide total fungal growth inhibition. According to our results, the antifungal properties of membranes depend on the graphene content in the sample. This observation may be explained by the larger surface area of PVDF_0.33G and PVDF_0.5G compared with other samples, which could have promoted further interactions with the fungal cells. In general, antimicrobial properties of graphene-based materials increase with the graphene concentration [43]. 
Nevertheless, the antimicrobial surface properties should be considered as the synergistic results of the surface chemical composition and surface topography [44]. For example, some studies have reported the potential use of superhydrophobic surfaces in preventing biofilm formation $[45,46]$. Other studies revealed that an increase in surface roughness did not influence or even inhibit the adhesion of bacteria [47,48]. Perera-Costa et al. [49] created various surface patterns on polydimethylsiloxane (PDMS). The results indicated that all patterned surfaces were distinguished by a significant reduction in bacterial adhesion in contrast to the flat surfaces. In our studies, the addition of GNP to the polymeric matrix significantly influenced the topographic features of the membrane surface, as described in detail in the previous paragraphs. Thus, the weaker antifungal activity of PVDF_5G and PVDF_10G may be a direct result of their inferior water-repellent properties and less-rough surface compared with PVDF_0.33G and PVDF_0.5G samples. However, further studies are needed for a deeper analysis of cell-surface interactions in the case of graphene-based membranes and evaluation of the importance of different surface topography. Nevertheless, it can be stated that the inhibition of fungal growth showed by PVDF_0.33G and PVDF_0.5G is a promising result for the development of an antibiofouling membrane. Surface properties, such as hydrophobicity and topography, prevent biofilm formation through the inhibition of microorganism adhesion, whereas graphene addition provides the toxicity effect of oxidative stress against them.

\section{Conclusions}

In this work, PVDF/graphene composite membranes were successfully fabricated by a phase inversion method. GNPs were well-dispersed in the PVDF membrane matrix when low nanofiller loading was used ( 0.33 and $0.5 \mathrm{wt} \%$ ), which was confirmed by SEM images. Among all the PVDF/GNP fabricated membranes, thePVDF_0.5G membrane (i.e., $0.5 \mathrm{wt} \%$ graphene loading) exhibited the most suitable properties in terms of pore size $(\sim 0.56 \mu \mathrm{m})$, porosity $(\sim 69 \%$,$) and hydrophobicity \left(\sim 139.5^{\circ}\right)$ for application to water desalination in the MD process. When GNP concentration was increased to over $0.5 \mathrm{wt} \%$, the prepared membranes tended to have smaller pore size, lower overall porosity, and lower water CA values than that of the PVDF_0.5G membrane, which could be due to the nanofiller agglomeration. Notably, the highest antifungal inhibition against Curvularia sp. fungal strain was observed in the PVDF_0.5G membrane. The results found in this work indicate that well-dispersed graphene nanoplatelets in aPVDF membrane matrix can be potentially useful in real seawater desalination and disinfection using MD approaches.

Author Contributions: E.G.-C., membrane preparation and characterization, and writing-original draft; M.K.R., funding acquisition and editing; R.C.-M., writing-review and editing; M.M.-J., antifungal activity investigations; B.B.-H., supervision of antifungal activity investigations; M.L., supervision, review, and editing. All authors have read and agreed to the published version of the manuscript.

Funding: This research received no external funding.

Institutional Review Board Statement: Not applicable.

Informed Consent Statement: Not applicable.

Data Availability Statement: The data presented in this study is available on request from the corresponding author.

Acknowledgments: R. Castro-Muñoz acknowledges the School of Science and Engineering and the FEMSA-Biotechnology Center at Tecnológico de Monterrey for their support through the Bioprocess (0020209I13) Focus Group. Financial support from the Polish National Agency for Academic Exchange (NAWA) under Ulam Programme (agreement no. PPN/ULM/2020/1/00005/U/00001) is also gratefully acknowledged. M.K. Rybarczyk would like to acknowledge the COST Action CA15107 Multicomp, supported by the COST Association (European Cooperation in Science and Technology).

Conflicts of Interest: The authors declare no conflict of interest. 


\section{References}

1. Greenlee, L.F.; Lawler, D.F.; Freeman, B.D.; Marrot, B.; Moulin, P. Reverse Osmosis Desalination: Water Sources, Technology, and Today's Challenges. Water Res. 2009, 43, 2317-2348. [CrossRef]

2. Castro-Muñoz, R. Breakthroughs on Tailoring Pervaporation Membranes for Water Desalination: A Review. Water Res. 2020, 187, 116428. [CrossRef] [PubMed]

3. Figoli, A.; Simone, S.; Criscuoli, A.; Al-Jlil, S.A.; Al Shabouna, F.S.; Al-Romaih, H.S.; Di Nicolò, E.; Al-Harbi, O.A.; Drioli, E. Hollow Fibers for Seawater Desalination from Blends of PVDF with Different Molecular Weights: Morphology, Properties and VMD Performance. Polymer 2014, 55, 1296-1306. [CrossRef]

4. Pichardo-Romero, D.; Garcia-Arce, Z.P.; Zavala-Ramírez, A.; Castro-Muñoz, R. Current Advances in Biofouling Mitigation in Membranes for Water Treatment: An Overview. Processes 2020, 8, 182. [CrossRef]

5. Rybarczyk, M.K.; Gontarek-Castro, E.; Ollik, K.; Lieder, M. Biomass-Derived Nitrogen Functionalized Carbon Nanodots and Their Anti-Biofouling Properties. Processes 2021, 9, 61. [CrossRef]

6. Hwang, B.K.; Lee, W.N.; Park, P.K.; Lee, C.H.; Chang, I.S. Effect of Membrane Fouling Reducer on Cake Structure and Membrane Permeability in Membrane Bioreactor. J. Memb. Sci. 2007, 288, 149-156. [CrossRef]

7. Charfi, A.; Ben Amar, N.; Harmand, J. Analysis of Fouling Mechanisms in Anaerobic Membrane Bioreactors. Water Res. 2012, 46, 2637-2650. [CrossRef] [PubMed]

8. Hliavitskaya, T.; Plisko, T.; Pratsenko, S.; Bildyukevich, A.; Lipnizki, F.; Rodrigues, G.; Sjölin, M. Development of Antifouling Ultrafiltration PES Membranes for Concentration of Hemicellulose. J. Appl. Polym. Sci. 2021, 138, 1-14. [CrossRef]

9. Ayyavoo, J.; Nguyen, T.P.N.; Jun, B.M.; Kim, I.C.; Kwon, Y.N. Protection of Polymeric Membranes with Antifouling Surfacing via Surface Modifications. Colloids Surfaces A Physicochem. Eng. Asp. 2016, 506, 190-201. [CrossRef]

10. Li, Q.; Imbrogno, J.; Belfort, G.; Wang, X.-L. Making Polymeric Membranes Antifouling via "Grafting from" Polymerization of Zwitterions. J. Appl. Polym. Sci. 2015, 132, 41781. [CrossRef]

11. Gontarek-Castro, E.; Castro-Muñoz, R.; Lieder, M. New Insights of Nanomaterials Usage toward Superhydrophobic Membranes for Water Desalination via Membrane Distillation: A Review. Crit. Rev. Environ. Sci. Technol. 2021, 1-46. [CrossRef]

12. Papageorgiou, D.G.; Kinloch, I.A.; Young, R.J. Mechanical Properties of Graphene and Graphene-Based Nanocomposites. Prog. Mater. Sci. 2017, 90, 75-127. [CrossRef]

13. Castro-Muñoz, R.; Buera-González, J.; de la Iglesia, Ó.; Galiano, F.; Fíla, V.; Malankowska, M.; Rubio, C.; Figoli, A.; Téllez, C.; Coronas, J. Towards the Dehydration of Ethanol Using Pervaporation Cross-Linked Poly(Vinyl Alcohol)/Graphene Oxide Membranes. J. Memb. Sci. 2019, 582, 423-434. [CrossRef]

14. Sun, P.; Wang, K.; Zhu, H. Recent Developments in Graphene-Based Membranes: Structure, Mass-Transport Mechanism and Potential Applications. Adv. Mater. 2016, 28, 2287-2310. [CrossRef] [PubMed]

15. Gontarek, E.; Macedonio, F.; Militano, F.; Giorno, L.; Lieder, M.; Politano, A.; Drioli, E.; Gugliuzza, A. Adsorption-Assisted Transport of Water Vapour in Super-Hydrophobic Membranes Filled with Multilayer Graphene Platelets. Nanoscale 2019, 11, 11521-11529. [CrossRef] [PubMed]

16. De Carvalho, A.P.A.; Conte Junior, C.A. Green Strategies for Active Food Packagings: A Systematic Review on Active Properties of Graphene-Based Nanomaterials and Biodegradable Polymers. Trends Food Sci. Technol. 2020, 103, 130-143. [CrossRef]

17. Zou, X.; Zhang, L.; Wang, Z.; Luo, Y. Mechanisms of the Antimicrobial Activities of Graphene Materials. J. Am. Chem. Soc. 2016, 138, 2064-2077. [CrossRef]

18. Liu, S.; Zeng, T.H.; Hofmann, M.; Burcombe, E.; Wei, J.; Jiang, R.; Kong, J.; Chen, Y. Antibacterial Activity of Graphite, Graphite Oxide, Graphene Oxide, and Reduced Graphene Oxide: Membrane and Oxidative Stress. ACS Nano 2011, 5, 6971-6980. [CrossRef]

19. Sawangphruk, M.; Srimuk, P.; Chiochan, P.; Sangsri, T.; Siwayaprahm, P. Synthesis and Antifungal Activity of Reduced Graphene Oxide Nanosheets. Carbon 2012, 50, 5156-5161. [CrossRef]

20. Aguas, Y.; Hincapie, M.; Fernández-Ibáñez, P.; Polo-López, M.I. Solar photocatalytic disinfection of agricultural pathogenic fungi (Curvularia sp.) in real urban wastewater. Sci. Total Environ 2017, 607-608, 1213-1224. [CrossRef]

21. Sun, H.Y.; Wang, H.C.; Chen, Y.; Li, H.X.; Chen, C.J.; Zhou, M.G. Multiple Resistance of Botrytis Cinerea from Vegetable Crops to Carbendazim, Diethofencarb, Procymidone, and Pyrimethanil in China. Plant Dis. 2010, 94, 551-556. [CrossRef]

22. Mirón-Mérida, V.A.; Yáñez-Fernández, J.; Montañez-Barragán, B.; Barragán Huerta, B.E. Valorization of Coffee Parchment Waste (Coffea Arabica) as a Source of Caffeine and Phenolic Compounds in Antifungal Gellan Gum Films. LWT 2019, 101, 167-174. [CrossRef]

23. Athanasekou, C.; Sapalidis, A.; Katris, I.; Savopoulou, E.; Beltsios, K.; Tsoufis, T.; Kaltzoglou, A.; Falaras, P.; Bounos, G.; Antoniou, M.; et al. Mixed Matrix PVDF/Graphene and Composite-Skin PVDF/Graphene Oxide Membranes Applied in Membrane Distillation. Polym. Eng. Sci. 2019, 59, E262-E278. [CrossRef]

24. Woo, Y.C.; Kim, Y.; Shim, W.G.; Tijing, L.D.; Yao, M.; Nghiem, L.D.; Choi, J.S.; Kim, S.H.; Shon, H.K. Graphene/PVDF Flat-Sheet Membrane for the Treatment of RO Brine from Coal Seam Gas Produced Water by Air Gap Membrane Distillation. J. Memb. Sci. 2016, 513, 74-84. [CrossRef]

25. Li, X.; Shan, H.; Cao, M.; Li, B. Facile Fabrication of Omniphobic PVDF Composite Membrane via a Waterborne Coating for Anti-Wetting and Anti-Fouling Membrane Distillation. J. Memb. Sci. 2019, 589, 117262. [CrossRef]

26. An, A.K.; Lee, E.J.; Guo, J.; Jeong, S.; Lee, J.G.; Ghaffour, N. Enhanced Vapor Transport in Membrane Distillation via Functionalized Carbon Nanotubes Anchored into Electrospun Nanofibres. Sci. Rep. 2017, 7, 1-11. 
27. Boo, C.; Lee, J.; Elimelech, M. Engineering Surface Energy and Nanostructure of Microporous Films for Expanded Membrane Distillation Applications. Environ. Sci. Technol. 2016, 50, 8112-8119. [CrossRef] [PubMed]

28. Deka, B.J.; Guo, J.; Khanzada, N.K.; An, A.K. Omniphobic Re-Entrant PVDF Membrane with ZnO Nanoparticles Composite for Desalination of Low Surface Tension Oily Seawater. Water Res. 2019, 165, 114982. [CrossRef] [PubMed]

29. Razmjou, A.; Arifin, E.; Dong, G.; Mansouri, J.; Chen, V. Superhydrophobic Modification of TiO2 Nanocomposite PVDF Membranes for Applications in Membrane Distillation. J. Memb. Sci. 2012, 415-416, 850-863. [CrossRef]

30. Ray, S.S.; Lee, H.K.; Kwon, Y.N. Review on Blueprint of Designing Anti-Wetting Polymeric Membrane Surfaces for Enhanced Membrane Distillation Performance. Polymers 2020, 12, 23. [CrossRef]

31. Nallasamy, P.; Mohan, S. Vibrational Spectroscopic Characterization of Form II Poly(Vinylidene Fluoride). Indian J. Pure Appl. Phys. 2005, 43, 821-827.

32. Woo, Y.C.; Lee, J.J.; Tijing, L.D.; Shon, H.K.; Yao, M.; Kim, H.S. Characteristics of Membrane Fouling by Consecutive Chemical Cleaning in Pressurized Ultrafiltration as Pre-Treatment of Seawater Desalination. Desalination 2015, 369, 51-61. [CrossRef]

33. Lai, Y.; Wan, L.; Wang, B. PVDF/Graphene Composite Nanoporous Membranes for Vanadium Flow Batteries. Membranes 2019, 9 , 89. [CrossRef] [PubMed]

34. Sun, G.; Li, X.; Qu, Y.; Wang, X.; Yan, H.; Zhang, Y. Preparation and Characterization of Graphite Nanosheets from Detonation Technique. Mater. Lett. 2008, 62, 703-706. [CrossRef]

35. Cai, X.; Lei, T.; Sun, D.; Lin, L. A Critical Analysis of the $\alpha, \beta$ and $\gamma$ Phases in Poly(Vinylidene Fluoride) Using FTIR. RSC Adv. 2017, 7, 15382-15389. [CrossRef]

36. Yang, Z.; Hao, X.; Chen, S.; Ma, Z.; Wang, W.; Wang, C.; Yue, L.; Sun, H.; Shao, Q.; Murugadoss, V.; et al. Long-Term Antibacterial Stable Reduced Graphene Oxide Nanocomposites Loaded with Cuprous Oxide Nanoparticles. J. Colloid Interface Sci. 2019, 533, 13-23. [CrossRef]

37. Duan, L.; Wang, Y.; Zhang, Y.; Liu, J. Graphene Immobilized Enzyme/Polyethersulfone Mixed Matrix Membrane: Enhanced Antibacterial, Permeable and Mechanical Properties. Appl. Surf. Sci. 2015, 355, 436-445. [CrossRef]

38. Castro-Muñoz, R. The Role of New Inorganic Materials in Composite Membranes for Water Disinfection. Membranes 2020, 10, 101. [CrossRef]

39. Kumar, P.; Huo, P.; Zhang, R.; Liu, B. Antibacterial Properties of Graphene-Based Nanomaterials. Nanomaterials 2019, 9, 737. [CrossRef] [PubMed]

40. Akhavan, O.; Ghaderi, E. Toxicity of Graphene and Graphene Oxide Nanowalls against Bacteria. ACS Nano 2010, 4, 5731-5736. [CrossRef]

41. Smith, S.C.; Rodrigues, D.F. Carbon-Based Nanomaterials for Removal of Chemical and Biological Contaminants from Water: A Review of Mechanisms and Applications. Carbon 2015, 91, 122-143. [CrossRef]

42. Chen, J.; Deng, F.; Hu, Y.; Sun, J.; Yang, Y. Antibacterial Activity of Graphene-Modified Anode on Shewanella Oneidensis MR-1 Biofilm in Microbial Fuel Cell. J. Power Sources 2015, 290, 80-86. [CrossRef]

43. Zhu, J.; Wang, J.; Hou, J.; Zhang, Y.; Liu, J.; Van der Bruggen, B. Graphene-Based Antimicrobial Polymeric Membranes: A Review. J. Mater. Chem. A. 2017, 5, 6776-6793. [CrossRef]

44. Wu, S.; Zhang, B.; Liu, Y.; Suo, X.; Li, H. Influence of Surface Topography on Bacterial Adhesion: A Review (Review). Biointerphases 2018, 13, 060801. [CrossRef]

45. Lin, C.; Tang, P.; Zhang, W.; Wang, Y.; Zhang, B.; Wang, H.; Zhang, L. Effect of Superhydrophobic Surface of Titanium on Staphylococcus Aureus Adhesion. J. Nanomater. 2011, 2011, 1-8.

46. Crick, C.R.; Ismail, S.; Pratten, J.; Parkin, I.P. An Investigation into Bacterial Attachment to an Elastomeric Superhydrophobic Surface Prepared via Aerosol Assisted Deposition. Thin Solid Films 2011, 519, 3722-3727. [CrossRef]

47. Rizzello, L.; Sorce, B.; Sabella, S.; Vecchio, G.; Galeone, A.; Brunetti, V.; Cingolani, R.; Pompa, P.P. Impact of Nanoscale Topography on Genomics and Proteomics of Adherent Bacteria. ACS Nano 2011, 5, 1865-1876. [CrossRef]

48. Lüdecke, C.; Roth, M.; Yu, W.; Horn, U.; Bossert, J.; Jandt, K.D. Nanorough Titanium Surfaces Reduce Adhesion of Escherichia Coli and Staphylococcus Aureus via Nano Adhesion Points. Colloids Surf. B 2016, 145, 617-625. [CrossRef]

49. Perera-Costa, D.; Bruque, J.M.; González-Martín, M.L.; Gómez-García, A.C.; Vadillo-Rodríguez, V. Studying the Influence of Surface Topography on Bacterial Adhesion Using Spatially Organized Microtopographic Surface Patterns. Langmuir 2014, 30, 4633-4641. [CrossRef] [PubMed] 